Special issue of the 3rd International Conference on Computational and Experimental Science and Engineering (ICCESEN 2016)

\title{
Experimental Self-Tuning Proportional Integral Derivative pH Control: Application to a Bioprocess
}

\author{
S. Altuntaş ${ }^{a, *}$, H. HapoĞLu ${ }^{b}$, S. ERtunç ${ }^{b}$ And M. Alpbaz \\ ${ }^{a}$ Ministry of Environment and Urbanization, Department of EU Investments, Ankara, Turkey \\ ${ }^{b}$ Ankara University, Department of Chemical Engineering, Ankara, Turkey
}

\begin{abstract}
$\mathrm{pH}$ control has received considerable attention in preparation of cheese whey drink, by fermentation with kefir yeast, because of its critical role in quality assurance. To improve the rheological and sensory properties of this drink, milk and grape juice are added to the bioprocess medium. Cheese whey drink was produced from the pasteurized mixture, which contains cheese whey, glucose, grape juice and milk. The fermentation of this mixture with kefir yeast in a batch bioreactor was investigated. The $\mathrm{pH}$ was monitored during the production of cheese whey drink. Experiments show that kefir yeast is very resistant to contamination. A self-tuning proportionalintegral-derivative control was applied to the bioprocess. The software of controller was developed by using the autoregressive moving average exogenous model. The model parameters were evaluated from input-output data by using a pseudo random binary sequence. The experimental results illustrate that the controller can maintain the $\mathrm{pH}$ at the desired value. It is noted that the self-tuning proportional-integral-derivative $\mathrm{pH}$ control results with the best controller tuning parameters and provides very good results, compared to initially adjusted case, without control. The best tuning parameters were found as $t_{1}=0.1, t_{2}=0, t_{3}=0$, by comparing experimental application results.
\end{abstract}

DOI: 10.12693/APhysPolA.132.1006

PACS/topics: Experimental self-tuning proportional-integral-derivative application, pH control, kefir yeast, cheese whey

\section{Introduction}

Cheese whey is a by-product of the cheese making process. Waste of the cheese-whey represents a significant loss of resources and causes serious pollution problems. There are several published papers, that dealt with biotechnological utilization of cheese whey [1-9].

Kourkoutas et al. [10] proposed a low-alcohol content drink by using continuous whey fermentation, using kefir yeast. It was reported that kefir was highly resistant to contamination under actual industrial conditions and no serious problems in handling of raw materials and equipment were observed [11]. Paraskevopoulou et al. [12] prepared a kefir-type drink by fermentation with kefir granules of cheese whey, containing fructose, black raisin extract and milk.

The ultimate measure of food quality is determined by comparing instrumental process set point. Food process control relies on instrumental measurements. Temperature and $\mathrm{pH}$ directly affect the microbial growth. As widely reported in the literature, optimal values of both temperature and $\mathrm{pH}$ exist and any deviation from these values may indeed result in a significant change of food quality.

Tan et al. [13] developed a robust self-tuning PID controller, which is suitable for nonlinear systems. Huang et al. [14] simulated a dyeing process, with the aim of bringing the $\mathrm{pH}$ of the liquor from any initial value to any

*corresponding author; e-mail: seminaltuntas@hotmail.com other value. They developed a self-tuning proportionalintegral-derivative (PID) controller with the ability to auto-tune the gains by extending model reference adaptive control. Alpbaz et al. [15] realized the $\mathrm{pH}$ control of the neutralization process of limestone with $\mathrm{H}_{2} \mathrm{SO}_{4}$ in a stirred continuous reactor by utilizing self-tuning PID algorithm. Altinten et al. [16] applied self-tuning PID controller, with genetic algorithm, to the temperature control of a jacketed batch polymerization reactor and thus tracking performance of optimal temperature profile was investigated. Vural et al. [17] studied the efficiency of $\mathrm{pH}$ control in the nonlinear region in a tubular flow reactor by using three different control strategies of conventional PID, self-tuning PID and fuzzy algorithms.

In this work, cheese whey drink was produced with kefir yeast by controlling the $\mathrm{pH}$ value of bioreactor medium with STPID control strategy. Such control of $\mathrm{pH}$ has a critical role in quality assurance.

\section{Self-tuning PID control}

A generally used process model is a controlled auto regressive moving average model (CARMA) or auto regressive moving average exogenous (ARMAX) model [18-20].

$$
A\left(z^{-1}\right) y(t)=z^{-k} B\left(z^{-1}\right) u(t)+C\left(z^{-1}\right) e(t),
$$

where $A, B$ and $C$ are polynomials in the backward shift operator $z^{-1}$, and $k$ is the system time delay, associated with the control input. $A$ and $B$ represent the poles and zeros of the discrete time system, respectively. $C$ contains the zeros of process noise and $e(t)$ is an uncorrected random sequence. $y(t)$ is system output at time $t$ and $u(t)$ is system input. 
In self-tuning control [9], the model parameters are estimated on-line and the controller settings, based on current parameter estimator are adjusted. The self-tuning approach has received more attention than any other adaptive control strategy. A generally used process model is CARMA, with a form of least square parameter estimation. CARMA model can be given as

$$
y(t)=x^{T}(t) \theta^{T}+e(t)
$$

where $\theta$ and $x$ are given by:

$$
\begin{aligned}
& \theta^{T}=\left[a_{1}, a_{2}, \ldots, a_{n a}, b, b_{1}, \ldots, b_{n b}, d, c_{1}, c_{2}, \ldots, c_{n c}\right], \\
& x^{T}=[y(t-1), y(t-2), \ldots, y(t-n a), \\
& \quad u(t-1), u(t-2), \ldots, u(t-n b-1), \\
& \quad 1, e(t-1), \ldots, e(t-n c)] .
\end{aligned}
$$

The discrete form of the PID control algorithm can be converted into a self-tuning equivalent. The control equation is given as follows:

$$
U(t)=(S / R)[r(t)-y(t)] .
$$

Here $r(t)$ represents the set point, and

$$
\begin{aligned}
& S=s_{0}+s_{1} z^{-1}+s_{2} z^{-2}, \\
& s_{0}=K_{c}\left(1+\frac{\Delta t}{2 \tau_{I}}+\frac{\tau_{D}}{\Delta t}\right), \\
& s_{1}=K_{C}\left(-1+\frac{\Delta t}{2 \tau_{I}}-\frac{2 \tau_{D}}{\Delta t}\right), \\
& s_{2}=K_{C}\left(\frac{\tau_{D}}{\Delta t}\right) \text { and } R=\left(1-z^{-1}\right) .
\end{aligned}
$$

Here $\Delta t$ is the sampling interval. The PID constants can be found from the values of $s_{0}, s_{1}$ and $s_{2}$. By substitution of the control equation into CARMA, process model yields the following closed-loop response equation:

$$
y(t)=\frac{z^{-1} B S}{A R+z^{-1} B S} r(t)+\frac{R C}{A R+z^{-1} B S} e(t) .
$$

The characteristic equation is called as Tailoring polynomial $T$ and it is given by:

$$
T\left(z^{-1}\right)=A\left(z^{-1}\right) R+z^{-k} B\left(z^{-1}\right) S\left(z^{-1}\right) .
$$

The properties of this closed-loop can be varied by placing the poles of the characteristic equation within the unit-circle in the $z$ plane. The coefficients of the $A$ and $B$ polynomials are estimated from the Bierman $U D U^{T}$ algorithm [21] and the coefficients of the $T$-polynomial are defined by user. $s_{0}, s_{1}$ and $s_{2}$ can be found from the characteristic Eq. (11).

The degrees of the polynomials in the characteristic equation are:

$$
n_{a}+n_{r}=n_{b}+n_{s}+1=n_{t},
$$

where $n_{s}$ is the order of $s$ and it is taken as 2 , and $n_{r}$ is the order of $r$ polynomial. Its value must be 1 , because of the polynomial representation of velocity form of the PID algorithm. In this case, the system transfer function is chosen is a third order $T$ polynomial $\left(n=2, n_{b}=1\right)$ and has the form:

$$
y(t)=\frac{b_{0} z^{-1}}{1+a_{1} z^{-1}+a_{2} z^{-2}} u(t) .
$$

The closed loop relationship is obtained by combining the system model equation (Eq. (13)) and the controller equation (Eq. (5)) as

$$
y(t)=\frac{b_{0} z^{-1} S}{R\left(1+a_{1} z^{-1}+a_{2} z^{-2}\right)+b_{0} z^{-1} S} r(t) .
$$

The equivalent chosen closed loop $T$ polynomial is of the form:

$$
T=1+t_{1} z^{-1}+t_{2} z^{-2}+t_{3} z^{-3} .
$$

By equating the denominator of Eq. (14) with Eq. (15), the following relationships are obtained:

$$
\begin{aligned}
& s_{0}=\frac{\left(t_{1}-a_{1}+1\right)}{b_{0}}, \\
& s_{1}=\frac{\left(t_{2}-a_{2}+a_{1}\right)}{b_{0}},
\end{aligned}
$$

and:

$$
s_{2}=\frac{\left(t_{3}-a_{2}\right)}{b_{0}} .
$$

The discrete form of the necessary incremental PID control law may be written in terms of the change in the control signal as

$$
\Delta U=s_{0} \varepsilon(t)+s_{1} \varepsilon(t-1)+s_{2} \varepsilon(t-2) .
$$

\section{Materials and methods}

The bioreactor with a cooling jacket and a volume of $1 \mathrm{l}$, used in the experiments, is shown in Fig. 1. The pH was measured with a $\mathrm{pH}$ meter and was recorded on-line, at a frequency of $1 \mathrm{~s}$, by a computerized data acquisition system. The system model parameters were calculated using experimental input-output data obtained from the bioreactor. The PRBS signal was regulating the flow rate of $0.5 \mathrm{M}$ sodium bicarbonate $\left(\mathrm{NaHCO}_{3}\right)$. The system dynamic response data was obtained from the on-line $\mathrm{pH}$ monitor.

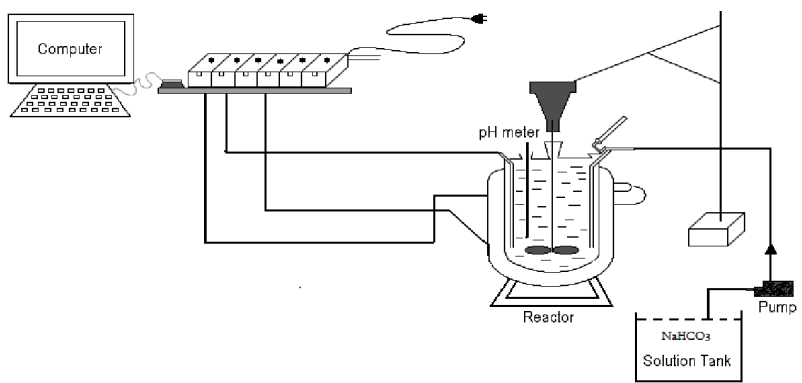

Fig. 1. Experimental setup.

In the experimental work, the bioreactor was first charged with pasteurized mixture, which contained $500 \mathrm{ml}$ of cheese whey, $10 \mathrm{~g}$ of glucose, $100 \mathrm{ml}$ of grape juice and $399 \mathrm{ml}$ of milk, and immediately inoculum (kefir yeast) was added. The temperature level was kept at $25^{\circ} \mathrm{C}$ by utilizing on-off control. A self-tuning PID control was 
applied to the bioprocess. The control response rise time was adjusted by adding gradually $0.5 \mathrm{M}$ citric acid. The software of controller was developed by using the autoregressive moving average exogenous model. The model parameters were evaluated from the experimental inputoutput data. The $\mathrm{pH}$ variable was monitored during fermentation.

The system model is given as:

$$
y(t)=\frac{B}{A} z^{-1} u(t)+\frac{C}{A} e(t),
$$

where $u(t)$ is base flow rate, $y(t)$ is $\mathrm{pH}$ value of the bioreactor mixture.

It is significant to note that integral action in the controller provides steady-state following without offset, even if the values of the parameters of the system or of the controller change.

\section{Results and discussion}

This experimental work was realized to monitor the $\mathrm{pH}$ change during the cheese whey drink production with kefir yeast. The temperature level of the bioprocess was kept at $25^{\circ} \mathrm{C}$ with on-off control. During the bioprocess, the $\mathrm{pH}$ decreases from the initial value of 6.9 to 3.9 within 8 hours (see figure in [1]). It is noted that the $\mathrm{pH}$ value should not decrease below a certain value, to avoid coagulation [1]. This decrease in $\mathrm{pH}$ necessitates the application of a control.

The controller design is generally based upon the process model, given in Eq. (1), thus fine-tuning is often required after the controller has been initially set up. On the other hand, self-tuning controllers can provide good control even if an accurate process model is not available.

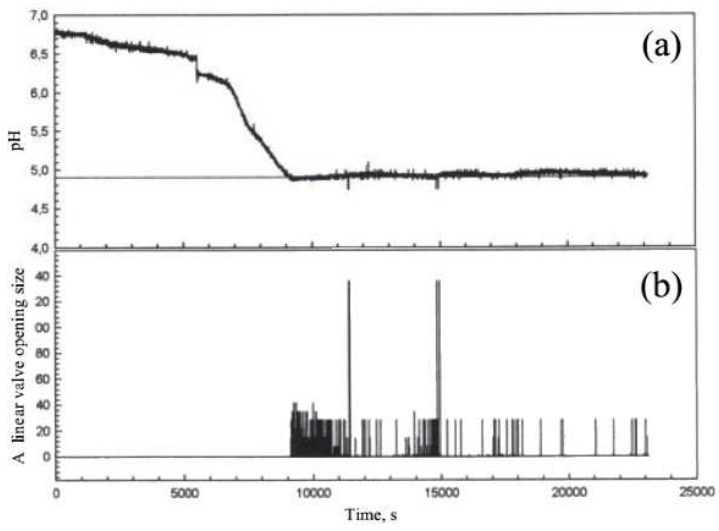

Fig. 2. The control of the $\mathrm{pH}$ under the effect of the STPID tuning parameter $t_{1}=0.1$, (a) variation with time of the close loop $\mathrm{pH}$, (b) variation with time of the close loop base flow rate ( $\{$ base flow rate, $\mathrm{ml} / \mathrm{min}\}=$ 0.019 , $\{$ linear valve opening size $\}=0.0025$ ).

As it is seen from the above figures, the best STPID tuning parameter value, obtained for $t_{1}$, equals to 0.1 . The effect of the STPID tuning parameter $t_{1}=0.01$ was tested experimentally.

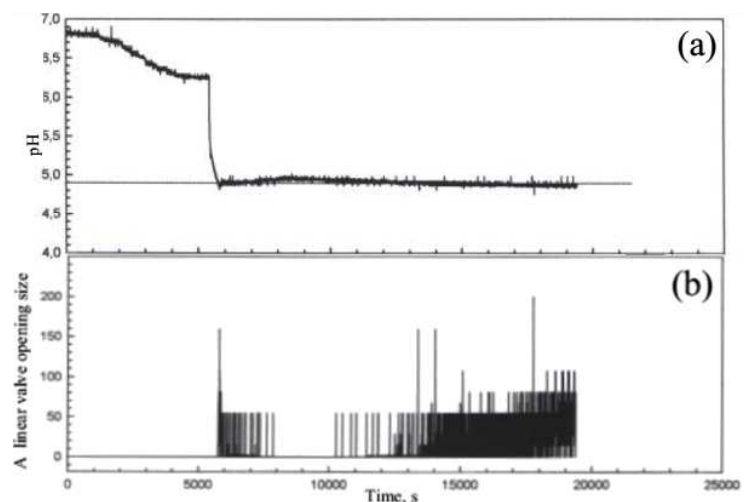

Fig. 3. The control of the pH under the effect of the STPID tuning parameter $t_{1}=0.9$ (a) variaton with time of the close loop $\mathrm{pH}$, (b) variation with time of the close loop base flow rate ( $\{$ base flow rate, $\mathrm{ml} / \mathrm{min}\}=0.019$, $\{$ linear valve opening size $\}=0.0025)$.

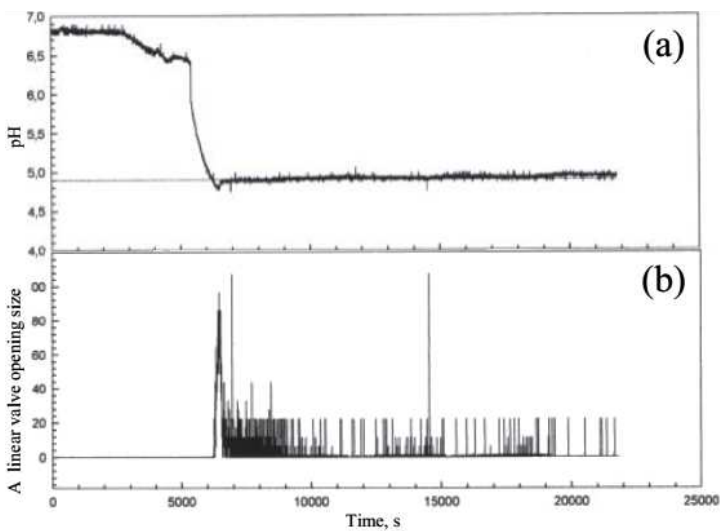

Fig. 4. The control of the $\mathrm{pH}$ under the effect of the STPID tuning parameter $t_{1}=0.01$, (a) variation with time of the close loop $\mathrm{pH}$, (b) variation with time of the close loop base flow rate ( $\{$ base flow rate, $\mathrm{ml} / \mathrm{min}\}=$ $0.019,\{$ linear valve opening size $\}=0.0025)$.

From the results of experimental $\mathrm{pH}$ control, given in Figs. 2-4, it was noted that suggested control system has shown a good performance in controlling the bioprocess. The $\mathrm{pH}$ control by using STPID algorithm with $t_{1}=0.01$ and $t_{1}=0.9$ had a similar performance. Conversely, the $\mathrm{pH}$ control by using STPID algorithm with $t_{1}=0.1$ had a performance which had differed from those of $t_{1}=0.01$ and $t_{1}=0.9$, due to the rise time. In general, it was assessed that the best $\mathrm{pH}$ control result was obtained by using STPID algorithm with $t_{1}=0.1$, regarding the adjusted rise time of $\sim 9000 \mathrm{~s}$.

\section{Nomenclature}

$A$ monic polynomial in the $z$-domain representing the poles of the discrete-time system

$B$ polynomial in the $z$-domain representing the zeros of the discrete-time system 
$C$ monic polynomial in the $z$-domain representing the zeros of the process noise

$e(t)$ white noise

$K_{c}$ steady-state gain for three term controller

$r(t)$ set point

$u(t)$ input variable at time $t$

$x$ data vector

$y(t)$ output variable at time $t$

$z, z^{-1}$ forward and backward shift operators

$t_{1}$ the first coefficient of the real denominator $T$ of the closed loop system model

$T$ the real denominator of the closed loop system model with STPID, which is of the form: $T=1+t_{1} z^{-1}+t_{2} z^{-2}+$ $t_{3} z^{-3}$

\section{Greek letters}

$\varepsilon(t)$ difference between the measured variable and set point at time $t$

$\tau_{D}$ derivative constant coefficient

$\tau_{I}$ integral constant coefficient

$\theta$ the parameter vector, defined as the collection of coefficients in the $A, B$, and $C$ polynomials.

\section{References}

[1] S. Altuntaş, S. Ertunç, H. Hapoğlu, M. Alpbaz, J. Engin. Architect. Faculty Eskişehir Osmangazi Univ. XXV, 31 (2012).

[2] S. Altuntaş, S. Ertunç, H. Hapoğlu, M. Alpbaz, Ordu Univ. J. Sci. Tech. 1, 15 (2011).

[3] M.R. Pedro, J. Guimaraes, A. Teixeira, L. Domingues, Biotechnol. Adv. 28, 375 (2010).

[4] S. Özmıhçı, F. Kargı, Enzyme Microbial Technol. 38, 711 (2006).

[5] S. Özmıhçı, F. Kargı, Biores. Technol. 98, 2978 (2007).
[6] S. Özmıhçı, F. Kargı, Enzyme Microbial Technol. 41, 876 (2007).

[7] S. Özmıhçı, F. Kargı, Biochem. Engin. J. 42, 180 (2008).

[8] A. Saraceno, S. Curcio, V. Calobro, G. Iorio, Comput. Chem. Engin. 34, 1590 (2010).

[9] S. Altuntaş, Ph.D. Thesis, Department of Chemical Engineering, Ankara University, 2012.

[10] Y. Kourkoutas, C. Psarianas, A.A. Koutinas, M. Kanellaki, I.M. Banat, R. Marchant, J. Agric. Food Chem. 50, 2543 (2002).

[11] I. Petsas, K. Psarianos, A. Bekatorov, A.A. Koutinas, I.M. Banat, R. Marchant, Biotechnol. Lett. 24, 557 (2002).

[12] A. Paraskevopoulou, I. Athanasiadis, G. Blekas, A.A. Koutinas, M. Kanellaki, V. Kiosseoglov, Food Hydrocolloids 17, 615 (2003).

[13] K.K. Tan, S. Huang, R. Ferdous, J. Process Control 12, 753 (2002).

[14] C.C. Huang, C.Y. Su, W.H. Yu, Textile Res. J. 70 195 (2000).

[15] M. Alpbaz, H. Hapoğlu, G. Özkan, S. Altuntaş, Chem. Engin. J. 116, 19 (2006).

[16] A. Altınten, F. Ketevanlioğlu, S. Erdoğan, H. Hapoğlu, M. Alpbaz, Chem. Engin. J. 138, 490 (2008).

[17] I.H. Vural, A. Altınten, H. Hapoğlu, S. Erdoğan, M. Alpbaz, Chinese J. Chem. Engin. 23, 154 (2015).

[18] D.E. Seborg, T.F. Edgar, S.L. Shah, AIChE J. 32, 881 (1986).

[19] R.B. Newell, P.L. Lee, Applied Process Control, Practical Hall, New York 1989.

[20] P.E. Wellstead, M.B. Zarrop, Self-Tuning Systems Control and Signal Processing, Wiley, Great Britain 1991.

[21] G.J. Bierman, Automatica 12, 375 (1976). 